\title{
THEORIES OF THE WILL AND KINÆSTHETIC SENSATIONS
}

BY RAYMOND H. WHEELER

University of Oregon

Theories of the will in psychology owe their origin to the development of ethical views among the early Greeks. These theories, together with those held by the early Church Fathers and the Scholastics, may be classified as intellectual and absolute. Both of these groups made will a faculty of the soul. The intellectual theories derived their name from the importance which they ascribe to the faculty of reason as a constituent of willing; the absolute theories made all other faculties of the soul subordinate to the will. In the Aristotelian view the will consisted of a 'desire' to which a 'goal' or an 'end' was supplied by the reason. Desire was analyzed as a persistent state of unrest or striving and was the essential active or dynamic feature of mental life. During the middle ages theories of the will were concerned largely with the problem of determinism versus freedom, hence the relative importance of the two faculties, the intellect and the will, as agents in controlling human behavior, was a subject of paramount importance.

As a consequence of empirical and inductive methods, we find in England from the time of Hobbes to Hume the development of a new type of theory, the emotional theory. Hume regarded the feelings as essential constituents of every volitional process. Locke had previously held that disquietude or uneasiness constituted the origin and the dynamic feature of volition, a view which in its essence was but a rehabilitation of Aristotle's potential desire. On the continent from Descartes to Herbart the tendency was gradually becoming definitized of conceiving the will as the active side of mental life in general, or as a general striving tendency.

Up to the time of more modern psychology, then, there 
were in general three views of the will. In a broad sense of the term the will included all mental activity as such, an activity characterized as a potential desire or as a state of unrest. This tendency culminated in a definitized theory of conation. Secondly there was a voluntaristic tendency to employ the term will itself to mean this active feature of mental life or the source and cause of action. Thirdly there was a tendency to bring the will into intimate relations with the feelings where the feelings were regarded as essential constituents of volitional processes.

Modern theories may be classified according to the feature most characteristic of each, namely its emphasis upon the reductivity or the non-reductivity of will to a complex grouping or mode of functioning of simpler constituents. Those theories which reduce will to a peculiar order of sequence of sensations, images and affections and which do not emphasize the elementary nature of any one constituent we may call the totally reductive. On the other hand those theories which admit the existence of an elementary mental content-an elementary and unique volitional process-may be called non-reductive. In this latter group the will has an elementary content which is not necessarily independent, functionally, from other contents. Intermediate between these two groups of theories is another which we may call the partially reductive. Here the will is reduced partly to the functioning of the traditional elements of consciousness and partly to a unique elemental content. The latter might be said to constitute a structural and functional criterion or an essential conscious concomitant of the volitional consciousness. This group may be subdivided thus: (I) those theories which posit a conative element; (2) those theories which posit an intrinsically active ego; (3) those which regard the feelings as the essential constituents of will; (4) those which ascribe to mental processes a force or general innervation mechanism. A final group of theories may be called motor or behavioristic owing to the fact that emphasis in them is laid upon the principle of stimulus and response. Here the will, reduced to its simplest terms, becomes a system of coördinated reflexes or motor responses and the innervation mechanisms are not mental but physiological. 
Non-reductive Theories.-Lotze ${ }^{1}$ conceived the will to be an unanalyzable psychic process which functioned chiefly in choice and resolve. Since it was not constantly functioning as a datum of consciousness it was relegated to the domain of the subconscious where it found a resting place when not actually in operation. In the more recent literature $\mathrm{Ach}^{2}$ and Michottes might be mentioned among those who, in consequence of their failure to analyze the volitional process experimentally and in consequence of finding a 'feeling of mental activity' in 'genuine' volitional acts, make a certain part of the volitional consciousness, at least, elemental and nonsensory. James' " most often quoted 'fiat' consciousness was a subjective experience sui-generis which could be designated but not defined.

Partially Reductive Theories.-Herbart's ${ }^{5}$ theory of the will is an early example of the conative theory. Here the will in its elemental form was to be found in the striving of ideas for existence in consciousness or for the possession of the conscious level. This striving process began in the realm of the unconscious. Volition consisted first of desire, a product of resistance between striving ideas and secondly in the opposition between groups of associated ideas (goals of purposes). Lipps ${ }^{6}$ assumed a striving process not only in ideas but in feelings and sensations as well. Both affective processes and feelings of activity were essential constituents of willing and of the volitional consciousness. The conationists, among whom may be mentioned Stout, ${ }^{7}$ especially, ascribe to each conscious state an inherent tendency to pass beyond itself into another conscious state, a striving process which is directly labelled conation and which, in itself, is present to consciousness.

Writing from the point of view of a self psychology Calkins described the content of willing as an active 'consciousness of

1 'Medicinische Psychologie,' Leipzig, I852.

' 'Ueber den Willensakt und das Temperament,' Leipzig, igro.

'Etude expérimentale sur le choix volontaire et ses antécédents immédiats,' Arch. de psychol, 10, 1910, 113-321.

'‘Principles of Psychology,' 1890, Vol. II.

' 'Lehrbuch der Psychologie,' Leipzig, 1850.

- 'Von Fühlen, Wollen und Deriken,' Leipzig, I902.

'A Manual of Psychology,' London, 1913. 
my active connection with other selves or with other things' ('First Book in Psychology,' 3 d rev. ed., p. 226). The volitional consciousness is said to involve the essential non-sensory factor of the 'self-as-willing.' Ach and Michotte found an immediate and unanalyzable consciousness of the self or an intrinsically active ego in all genuine volitional acts. Meumann' assumed that the process of 'accepting' a goal idea, in a volitional act, involved an immediate consciousness of the self. Both partially reductive and totally reductive tendencies can be found in the analyses of volition which have been made by these latter writers.

The emotional theory of the will may be illustrated by reference to Bain ${ }^{2}$ and Wundt. ${ }^{3}$ Bain defined the will as all mental and physical activities insofar as they were guided or impelled by the feelings of pleasure or pain. Wundt's theory (which is voluntaristic as well as emotional) makes will the original energy of consciousness, the first and primary form of which is a simple impulse motivated by pleasure or pain. When an organism experiences a simple sensation there arises a feeling process which develops to a maximal state of intensity beyond which it overflows into movement. Such a sensationfeeling-action series of experiences and events is called a simple or primary act of will. Feeling processes, therefore, possess an innate capacity toward willing. This is either a capacity to arouse physical movements or to initiate into consciousness other mental processes. In more complicated forms of will the feelings or emotions may be observed to increase gradually in their intensity, beginning with pleasantness or unpleasantness, eventually developing into strain or excitement. These feeling states fuse into a 'total feeling of activity' which is an essential conscious concomitant of complex or secondary acts of will. In this category are found such acts as choosing and performing difficult tasks. Secondary volitional acts may be motivated by ideas which are associated with the feelings.

As an example of a 'force' theory may be cited Fouillée'

1 'Intelligenz und Wille,' Leipzig, 1913.

2 'The Emotions and the Will,' London, 1899.

' 'Grundzüge der Physiologische Psychologie,' Leipzig, 1903.

' 'L'évolutionisme des idées-forces,' Paris, 1893. 
for whom sensations and feelings are at the same time conscious states and mental forces according to the viewpoint taken in regarding such mental processes as contents or as acts.

Totally Reductive Theories.-Münsterberg ${ }^{1}$ held that the will as a datum of consciousness was a goal-idea which had come to be associated with other ideas or with muscular movements. This goal-idea involved the anticipation of an end. In other words it is a mental process of sensory origin having to do with preparatory motor adjustments. Ebbinghaus ${ }^{2}$ in like manner held that volition consisted in the capacity to foresee the end of action by associating an image with an act in such fashion that the image would function as the stimulus for the subsequent act. In the views of $\mathrm{Ach}^{3}$ and Meumann ${ }^{4}$ we might have found totally reductive theories had it not been for the fact that both ultimately drag in a non-sensory experience pertaining to the self and feelings of activity. Meumann described the will as a selective process brought about by means of 'accepted' goal ideas, while in a similar fashion Ach found the clue to a volitional act in the acceptance of an Aufgabe. The capacity of goal-ideas to so control subsequent mental processes depended upon the previous forming of associations between the foresight of an end and the act which attained that end.

Behavioristic Theories.-The modern trend of descriptions of the will is obviously behavioristic, where the emphasis is laid upon the coördinated responses of the organism to its environment and not upon the mental contents as such. But owing to the lack of experimental evidence accurate accounts of the volitional process cannot be presented. According to Ribot $^{5}$ the will is to be regarded as the sum total of the organism's responses to environment. All mental processes tend to express themselves in some form of overt action and would succeed in doing so were it not for processes of inhibition. The continuity of mental states can be expressed only in terms of the continuity of these organized motor responses.

1 'Die Willenshandlung,' Freiburg, 1913.

2 'Grundzüge der Psychologie,' Leipzig, 1911.

'Loc. czt.

- Loc. cit.

'The Diseases of the Will' (trans.), Chicago, 1903. 
Notwithstanding the numerous descriptions and interpretations of the will which have appeared in the literature we find little genuine progress in ascertaining the exact characteristics of the volitional consciousness. It is evident, however, that it cannot be described adequately in terms of structural contents alone. Functionally, two distinct problems are involved, namely those of the will in a broader and in a narrower sense. In the broader sense the problem of the will should be identified with the problem of the general sequence of mental processes. Such discussions seek to answer the question, how may the sequence of mental processes be envisaged in mental terms? Or stating the problem in objective terms: how may the continuity of the organism's responses to environment be best described? In the narrower sense the will should be identified with the problem of a particular portion or order of sequence where the question is asked how may one group of mental processes exert an apparent directing influence over subsequent mental processes? Stated in objective terms: how may one response lead inevitably to the making of a subsequent response?

Theories which have been formulated from a subjective point of view have reduced the will, in the broader sense, to a potential desire (Aristotle), to a state of uneasiness (Locke), to a striving process (Herbart, Lipps), to a conative tendency (Stout, Baldwin and others) to an intrinsically active ego (Calkins, etc.), to innervating properties of the feelings or emotions (Bain, Wundt) and to an alleged dynamic force (Fouillee). Other writers have concerned themselves with the general problem of sequence but from an objective point of view; hence the will has become the sum total of the organism's motor responses (Ribot and others).

Still others who have faced the same problem and who have borne in mind both its structural and functional aspects have failed to find any structural clue to the general problem of sequence, hence for them the problem becomes one of a unique or particular order of sequence. Here, again, failing to find elementary structural clues they have formulated theories of a totally reductive character. In such theories the im- 
portant rôle is assigned to a goal-idea or $A$ ufgabe which conditions the sequence of mental processes by means of productive or selective influences. On the other hand there have been many attempts to state clearly the problem both in its broader and narrower aspects. For example, the will in its narrower sense (volition proper) was envisaged by Aristotle as a rational desire; by Hume, Bain and Wundt as a highly organized sequence of potential emotional processes associated with ideas; by the conationists as a highly organized conative system the distinctive feature of which was the foresight of an end. Another view involves an assertive attitude of the self (Calkins). The problems have been the same throughout all these discussions; but how different have been the solutions!

The confusion found in these descriptions can be traced obviously to widely different points of view. Advocates of partially reductive theories have been obliged to appeal either to a volitional constituent in the feelings, to an alleged conative element, to an intrinsically active ego or to forces inherent in sensation and affection in order to account for the general conscious continuum in purely subjective factors while adhering at the same time to an atomistic conception of mind. It is the problem of getting elementary states of consciousness back into a working, active system again after they have been assigned the rôle of units or 'atoms.' It is the problem of making a river out of a succession of barrels in the stream bed. Witness the attempts of those writers who adhere to an atomistic and structural conception of mind but who have failed to discover any elemental conscious experience whose constant presence in mental life will explain the continuity of conscious states. Such writers (James, ${ }^{1}$ Brentano, ${ }^{2}$ Witasek $^{3}$ ) have resorted to other factors such as to a differentiation between transitive and substantive states or between act and content. From a more objective point of view the recent motor movement in psychology seems to be based essentially upon an attempt to solve the general problem of sequence and unbroken continuum.

1 Loc. cit.

2 'Psychologie vom empirischen Standpunkte,' 1874.

s 'Grundlinien der Psychologie,' 1908. 
As for the narrower problem-the determination of subsequent processes by an antecedent process-one finds the same divergence in points of view and in results. The issue has been definitely sharpened by positing the existence of a determining tendency or directing of the course of the stream of consciousness. But this determining tendency may be either a driving, a vis a tergo exerted by the Aufgabe (Ach) or a leading -an attracting-by goal ideas (Meumann). Auxiliary principles such as associative tendencies, perseveration tendencies and constellations have been appealed to in an endeavor to formulate the problem and its solution more clearly. But the traditional principles of association have borne the burden throughout all these more recent discussions. The objective or behavioristic attack upon this same narrower problem includes the reflex-arc concept (Dewey) ${ }^{1}$ and the principle of ideo-motor action.

The solution of these problems has been delayed, also, because of the very meager introspective analyses which have so far been made under experimentally controlled conditions. It is extremely doubtful whether a genuinely vigorous volitional act has ever, in the past, been subjected to adequate introspection.

It seems to the writer that insofar as the partially reductive theories have been based upon introspective evidence, the trouble has been in a failure to reduce conation, striving process, feelings of activity, etc., to a common process. We have every reason to believe that many of Wundt's 'feelings,' for example, are forms of kinæsthetic sensations. Is it not quite probable that what the conationists have called the immediate conative experience is kinæsthetic sensation? The writer is firmly convinced that the 'feeling of mental activity' described by Ach and Michotte is a complex of kinæsthetic sensations. Moreover is it not also possible that Meumann's consciousness of the self in the acceptance of a task or that Professor Calkins's intrinsically active ego are interpretations unwittingly based upon an immediately experienced but complex and diffuse kinæsthetic background and nothing else? Within the last

1 'The Reflex Arc Concept in Psychology,' Psycrol. REv., 1896, 3, p. 357. 
few years there have appeared several elaborate introspective descriptions ${ }^{1}$ of various conscious processes but in none of these do we find the slightest hint of such elements. Kinæsthetic sensations are with us always in mental life. Recent introspective works and more especially those of Fernberger and the writer show the importance of such processes. In fact, as the writer has shown in an introspective study of choosing, ${ }^{2}$ kinæsthetic processes are essential and as a type the only essential form of elemental conscious process in the act of choosing.

It does not seem unwarranted, therefore, to conclude that the extreme variations in past descriptions of the will consciousness both in its broader and narrower aspects have been due to various interpretations of a consciousness which is so largely made up of kinæsthetic sensations. From these experiences we get our notions of striving, strain, activity, force, conation and the like. It may be open to question, also, whether the Freudian wish and its various cousins are not veiled and unconscious interpretations unwittingly based upon a consciousness of kinæsthetic strain.

To sum up, theories of the will in the history of psychology represent successive attempts to describe the conscious continuum as a whole and to describe the process of control in any given portion of the conscious continuum. The chief cause for the great variability of these descriptions lies in a further attempt to find evidence of this continuity in some unique mental process. Where such an elemental process has been found lacking we have been obliged to resort to the principle of act and content. Various points of view have added to the confusion. And in modern psychology, inadequate introspective data has led to inadequate interpretation. The unique mental process, we believe, is nothing more than kinæsthetic sensation.

'E. L. Woods, 'An Experimental Analysis of the Process of Recognizing,' Amer . J. of Psychol., 1915, 26, 313-387. S. C. Fisher, 'The Process of Generalizing; and its Product, the General Concept,' Psychol. Mon., 1916, 21, No. 2 (Whole No. 9o). S. W. Fernberger, 'An Introspective Analysis of the Process of Comparing,' Psychol. Mon., 1919, 26, No. 6 (Whole No. 117).

2 R. H. Wheeler, 'An Experimental Investigation of the Process of Choosing,' University of Oregon Publications, 1920, Vol. I, No. 2. 
This compels us to settle upon a point of view. It shows us the futility of searching for introspective evidence of continuity and places us in the position of the other sciences where we rightly should be-the position of finding continuity in data treated from an objective point of view. We should look for the solution of the problem, therefore, in behavioristic principles. The cry at present is, in some circles, to do away with introspection. But in the other sciences observations are made via the senses. Why can we not observe our own behavior in the same way? Introspection as sensory evidence of our own behavior ought to be as valid as sensory observation of any movement external to our bodies. Let the 'feel' of a response be as ample evidence of the existence of that response as the 'sight' of it in another person or an animal. To be sure introspective evidence should be verified wherever possible both by objective instruments and by similar reports from large numbers of observers. Our view is that in attempting to solve psychological problems in the future,--problems which were formally considered purely subjective-we are warranted in drawing behavioristic interpretations, in part at least, from introspective data. 